Materials Science and Engineering A 442 (2006) 336-341.

\title{
Elasticity study of very thin Cu films
}

\author{
K. Fujiwara, H. Tanimoto and H. Mizubayashi* \\ Institute of Materials Science, University of Tsukuba, Tsukuba, Ibaraki 305-8573, Japan
}

\begin{abstract}
The elastic property and the surface morphology of $\mathrm{Cu} / \mathrm{Ta}$ films and $\mathrm{Ta} / \mathrm{Cu} / \mathrm{Ta}$ films sputter-deposited on Si reed substrates were studied for the $\mathrm{Cu}$ film thickness, $t_{\mathrm{Cu}}$, between 7 and $1000 \mathrm{~nm}$. A monotonic increase in the internal friction, $Q^{-1}$, in the constituent $\mathrm{Cu}$ film above $200 \mathrm{~K}$ was commonly observed. For $\mathrm{Cu} / \mathrm{Ta}$ films, Young's modulus of a $\mathrm{Cu}$ film, $E_{\mathrm{f}}$, showed good agreement with the theoretical value for $t_{\mathrm{Cu}}>\sim 80 \mathrm{~nm}$ and a decrease with decreasing $t_{\mathrm{Cu}}$ below $\sim 80 \mathrm{~nm}$. A decrease in $Q_{\mathrm{f}}^{-1}$ after $400 \mathrm{~K}$ annealing, $\Delta Q_{\mathrm{f}, 400 \mathrm{~K}}^{-1}$, and the surface roughness showed the local minimum and the local maximum near $80 \mathrm{~nm}$, respectively, indicating that the properties of the $\mathrm{Cu}$ film were modified by subsequent deposition of a $\mathrm{Cu}$ layer (the self capping effect). For $\mathrm{Ta} / \mathrm{Cu} / \mathrm{Ta}$ films, Ta capping brought about an increase in the grain size parallel to the film surface, a decrease in the internal stress and a decrease in $E_{\mathrm{f}}$ but no changes in the grain size normal to the film surface, $Q_{\mathrm{f}}^{-1}$, $\Delta Q_{\mathrm{f}, 400 \mathrm{~K}}^{-1}$ and the outline of the surface roughness. These results are discussed in the light of the anelastic responses of grain boundaries and interface in nano-scale $\mathrm{Cu}$ films which may be important for down sizing of electric devices.
\end{abstract}

Keywords: $\mathrm{Cu}$ thin film, Young's modulus, Internal friction, Internal stress, Surface morphology, Capping effect

*Corresponding author. E-mail: mizubayashi@ims.tsukuba.ac.jp

\section{Introduction}

Understanding of the elastic property of nm-scale $\mathrm{Cu}$ interconnects is important for the semiconductor devices because the internal stress induced in $\mathrm{Cu} /$ low-dielectric-constant-material interconnects will be a serious issue because the low-dielectric-constant materials tend to be mechanically weak [1,2]. Further, electromigration and stress-induced migration (stressmigration) failures are of the most important issue in metallization, where the film thickness dependence of Young's modulus, the internal stress, the crystallographic texture, the grain size and the property of the grain boundaries should be understood [2-4], because the electromigration and stressmigration failures at the device operating temperature of $100{ }^{\circ} \mathrm{C}$ in real devices are induced by surface and/or interface diffusions [1]. In nanostructured metals, the fractional volume of the grain boundary regions and the surface and/or interface regions increase with decreasing grain size, film thickness and/or interconnect size. For nanostructured thin films and/or specimens of Al [5-7], $\mathrm{Cu}$ [8,9] $\mathrm{Au}[10,11]$, the grain boundary anelastic process (GBAP) is thermally activated above $200 \mathrm{~K}$ and causes an increase in the internal friction and a considerable 
decrease in Young's modulus. On the other hand, the internal friction peak due to the GBAP in bulk $\mathrm{Cu}$ is observed near $500 \mathrm{~K}$ [12], indicating that the atomic process in nanostructured $\mathrm{Cu}$ may be not in the extension from that in bulk $\mathrm{Cu}$. For the atomic transports in the surface and/or interface regions in $\mathrm{nm}$-scale $\mathrm{Cu}$ films, it has been reported that capping of $\mathrm{Cu}$ films brings about the elongation of the lifetime of electromigration failure [13] and the suppression of the diffusional creep [14] and the internal stress relaxation [15]. The underlying mechanisms for these characteristic phenomena are, however, not clear yet because of a lack of the experimental knowledge concerned.

Recently it was reported that for a $\mathrm{Cu}$ film on a Ta buffer layer deposited by sputtering, Young's modulus of the $\mathrm{Cu}$ film showed a decrease with decreasing $\mathrm{Cu}$ film thickness below about $100 \mathrm{~nm}$ [8]. It was further reported for the $\mathrm{Cu}$ film on a Ta buffer layer that the surface roughness showed the maximum at around $t_{\mathrm{Cu}} \approx 80 \mathrm{~nm}$ and the decrease of the internal friction caused by $400 \mathrm{~K}$ annealing showed the minimum at around $t_{\mathrm{Cu}} \approx 80 \mathrm{~nm}$, where $t_{\mathrm{Cu}}$ is the $\mathrm{Cu}$ film thickness [16]. In the present study, we investigated an effect of Ta capping on the characteristic elastic property and surface morphology found for a $\mathrm{Cu}$ film on a Ta buffer layer because $\mathrm{Cu}$ films and interconnects in real devices are always capped by a buffer layer.

\section{Experiment}

For the composite reed of a thin film on a reed-substrate, Young's modulus, $E_{\mathrm{f}}$, and the internal friction, $Q^{-1}$, of the film may be given by the following equations $[5,6]$,

$$
\begin{aligned}
& E_{\mathrm{f}}=\left(E_{\mathrm{s}} / 3\right)\left[2\left(\Delta f_{\mathrm{f}} / f_{\mathrm{s}}\right) /\left(t_{\mathrm{f}} / t_{\mathrm{s}}\right)+\left(\rho_{\mathrm{f}} / \rho_{\mathrm{s}}\right)\right]\left[\left(1-v_{\mathrm{f}}^{2}\right) /\left(1-v_{\mathrm{f}} v_{\mathrm{s}}\right)\right] \\
& Q^{-1}{ }_{\mathrm{f}}=\Delta Q^{-1}{ }_{\mathrm{f}}\left(t_{\mathrm{s}} / 3 t_{\mathrm{f}}\right)\left(E_{\mathrm{s}} / E_{\mathrm{f}}\right)
\end{aligned}
$$

where the subscripts of "f" and "s" denote the quantities for the film and the reed substrate, respectively. E, $t, \rho$ and $v$ denote Young's modulus, the film thickness, the density and Poisson ratio, respectively. In the present setup, the reed-substrate was a $\mathrm{Si}$ reed-substrate with a Ta buffer layer. $\Delta f_{\mathrm{f}} / f_{\mathrm{s}}$ and $\Delta Q^{-1}{ }_{\mathrm{f}}$ were defined as $\left(f_{\mathrm{s}+\mathrm{f}}-f_{\mathrm{s}}\right) / f_{\mathrm{s}}$ and $\left(Q^{-1}{ }_{\mathrm{s}+\mathrm{f}}-Q^{-1}{ }_{\mathrm{s}}\right)$, where $f_{\mathrm{s}}$ and $Q^{-1}{ }_{s}$ were the resonant frequency and the internal friction of the reed-substrate with a Ta buffer layer, and $f_{\mathrm{s}+\mathrm{f}}$ and $Q^{-1}{ }_{\mathrm{s}+\mathrm{f}}$ were the resonant frequency and internal friction of the composite reed of a $\mathrm{Cu}$ thin film on the reed substrate, respectively.

Figure 1(a) is a schematic drawing of a silicon reed-substrate with a thick end for clamping. A silicon reed-substrate was chemically etched and terminated by hydrogen prior to the metallization. Figure 1(b) is a schematic drawing of a measurement setup. The metallization was conducted by dc-sputtering at room temperature in $\operatorname{Ar}$ (6 $\mathrm{N}$ purity) at $1.3 \times 10^{-1} \mathrm{~Pa}$, where the deposition rate of $\mathrm{Cu}$ and Ta was 5 and $2 \mathrm{~nm} / \mathrm{min}$, respectively. Figure 1(c) shows schematic cross sectional views of a $\mathrm{Cu} / \mathrm{Ta}$ film and a $\mathrm{Ta} / \mathrm{Cu} / \mathrm{Ta}$ film. Firstly a 30 $\mathrm{nm}$ Ta buffer layer (Ta-1 in Fig. 1(c)) was deposited on a Si reed substrate and the resonant frequency, $f_{0}$, of the Si reed substrate with the Ta-1 layer was measured as shown in Figure 2(a). Then an additional Ta buffer layer (Ta-2 in Fig. 1(c)) and a $\mathrm{Cu}$ specimen film were deposited for a $\mathrm{Cu} / \mathrm{Ta}$ film. For a $\mathrm{Ta} / \mathrm{Cu} / \mathrm{Ta}$ film, the $\mathrm{Ta}-2$ layer, a $\mathrm{Cu}$ specimen film and a $\mathrm{Ta}$ cap layer (Ta-3 in Fig.(c)) were sequentially deposited. The thickness of the Ta-2 buffer layer was $30 \mathrm{~nm}$ for the $\mathrm{Cu} / \mathrm{Ta}$ films with the $\mathrm{Cu}$ film thickness, $t_{\mathrm{Cu}}$, more than $30 \mathrm{~nm}$ and was $5 \mathrm{~nm}$ for the thinner $\mathrm{Cu} / \mathrm{Ta}$ films and all the $\mathrm{Ta} / \mathrm{Cu} / \mathrm{Ta}$ films, respectively. The thickness of the Ta-3 cap layer was $5 \mathrm{~nm}$. A change in the resonant frequency, $\Delta f_{\text {Ta }}$, of a Si reed substrate due to deposition of the Ta-2 and the Ta-3 layers was separately calibrated. Figure 2(b) shows examples of $\Delta f_{30 \mathrm{nmTa}}$ observed for deposition of the $30 \mathrm{~nm}$ Ta-2 layer, where data $\Delta f_{30 \mathrm{nmTa}}=$ $0.3215 \pm 0.0173 \mathrm{~Hz}$ was found. In Fig. 2(a), the resonant frequency, $f_{1}$, of the Si reed substrate 
after deposition of the $30 \mathrm{~nm} \mathrm{Ta}-2$ buffer layer and the $40 \mathrm{~nm} \mathrm{Cu}$ film is shown. It is noted that $f_{\mathrm{s}+\mathrm{f}}$ and $f_{\mathrm{s}}$ in Eq. (1) are determined as $f_{1}$ and $\left(f_{0}+\Delta f_{30 \mathrm{nmTa}}\right)$ in Fig. 2(a), respectively or $\Delta f_{\mathrm{f}}$ $=\Delta f_{1-0}-\Delta f_{30 \mathrm{nmTa}}$ for a $\mathrm{Cu} / \mathrm{Ta}$ film. It is not shown here but the calibrations for $\Delta f_{5 \mathrm{nmTa}}$ and $\Delta Q^{-1} \mathrm{Ta}$ were also made separately.

The X-ray diffraction (XRD) measurement was performed with the $\mathrm{Cu}-\mathrm{K} \alpha$ radiation. The scattering vector was normal to the surface of a $\mathrm{Cu}$ film and the reflections from $\mathrm{Si}$ powders put on the film surface were used as reference. The surface morphology of $\mathrm{Cu} / \mathrm{Ta}$ and $\mathrm{Ta} / \mathrm{Cu} / \mathrm{Ta}$ films was observed by using the STM operating in the constant current mode at the atmosphere.

\section{Results}

In Figures 3(a) to 3(c), the fractional intensity of the XRD $\mathrm{Cu} 200$ reflection, $I_{200} /\left(I_{111}+I_{200}\right)$, the mean grain size, $D_{\perp(111)}$, in a $\mathrm{Cu}$ film and the (111) plane spacing normal to the surface of a $\mathrm{Cu}$ film, $d_{\perp(111)}$, are plotted as a function of the $\mathrm{Cu}$ film thickness, $t_{\mathrm{Cu}}$, respectively. For the $\mathrm{Cu} / \mathrm{Ta}$ films [16], the strong $<111>$ texture was observed for $t_{\mathrm{Cu}}$ thinner than about $100 \mathrm{~nm}$ and then $I_{200}$ started to increase with increasing $t_{\mathrm{Cu}}$ above about $100 \mathrm{~nm}$. It is noted that the strong $<111>$ texture was reported commonly for sputter deposited $\mathrm{Cu} / \mathrm{Ta}$ films $[4,17,18]$. For the $\mathrm{Ta} / \mathrm{Cu} / \mathrm{Ta}$ films, the values of $I_{200} /\left(I_{111}+I_{200}\right)$ appeared to be constant about 0.2 in the present $t_{\mathrm{Cu}}$ range from 20 to $300 \mathrm{~nm}$. It is noted that such change in $I_{200} /\left(I_{111}+I_{200}\right)$ was induced by $\mathrm{Ta}$ capping. For both the $\mathrm{Cu} / \mathrm{Ta}$ and $\mathrm{Ta} / \mathrm{Cu} / \mathrm{Ta}$ films, $I_{200} /\left(I_{111}+I_{200}\right)$ remained unchanged after annealing at $400 \mathrm{~K}$.

In Fig. 3(b), $D_{\perp(111)}$ was estimated from the peak width of the (111) reflection and the Scherrer's equation, where the experimental resolution for the upper bound of $D_{\perp(111)}$ was about $100 \mathrm{~nm}$. For both the $\mathrm{Cu} / \mathrm{Ta}$ films and the $\mathrm{Ta} / \mathrm{Cu} / \mathrm{Ta}$ films in the as deposited state, $D_{\perp(111)}$ increased gradually to about $100 \mathrm{~nm}$ with increasing $t_{\mathrm{Cu}}$ to $1000 \mathrm{~nm}$. For the $\mathrm{Cu} / \mathrm{Ta}$ films, $400 \mathrm{~K}$ annealing hardly changed $D_{\perp(111)}$ for $t_{\mathrm{Cu}}$ thinner than $100 \mathrm{~nm}$ and appeared to cause a slight increase in $D_{\perp(111)}$ for $t_{\mathrm{Cu}}$ thicker than $100 \mathrm{~nm}$. For the $\mathrm{Ta} / \mathrm{Cu} / \mathrm{Ta}$ films, $D_{\perp(111)}$ showed almost no change after annealing at $400 \mathrm{~K}$.

As seen in Fig. 3(c), with decreasing $t_{\mathrm{Cu}}, d_{\perp(111)}$ showed a gradual decrease for the $\mathrm{Cu} / \mathrm{Ta}$ films and remained almost unchanged for the $\mathrm{Ta} / \mathrm{Cu} / \mathrm{Ta}$ films, respectively. The internal

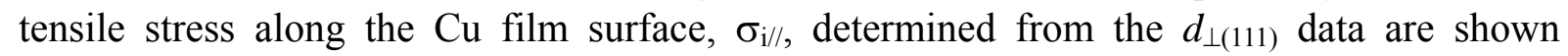
together, where a change in $d_{\perp(111)}$ from its reference value was assumed to be the Poisson contraction or expansion. As already mentioned for $I_{200} /\left(I_{111}+I_{200}\right)$, Ta capping caused a decrease in $\sigma_{\mathrm{i} / /}$ too.

Figure 4 shows the $E_{\mathrm{f}} v$ s. $t_{\mathrm{Cu}}$ data observed for the $\mathrm{Cu} / \mathrm{Ta}$ and $\mathrm{Ta} / \mathrm{Cu} / \mathrm{Ta}$ films, where the experimental errors were mainly associated with those in the calibrations for $\Delta f_{\text {Ta. }}$. For the $\mathrm{Cu} / \mathrm{Ta}$ films [16], $E_{\mathrm{f}}$ was almost the same to $E_{<110>}$ for $t_{\mathrm{Cu}}>\sim 80 \mathrm{~nm}$ and gradually decreased with decreasing $t_{\mathrm{Cu}}$ below $\sim 80 \mathrm{~nm}$, where the $E_{\mathrm{f}} v s$. $t_{\mathrm{Cu}}$ data for $t_{\mathrm{Cu}}>\sim 80 \mathrm{~nm}$ were well explained by the theoretical values of $E_{\mathrm{f}}$ estimated by taking into account the crystallographic texture (Fig. 3(a)) [7] and the internal stress (Fig. 3(c)) [19].

The values of $E_{\mathrm{f}}$ observed for $t_{\mathrm{Cu}}<\sim 80 \mathrm{~nm}$ was lower by $\sim 2 \times 10^{10} \mathrm{~Pa}$ than the theoretical values of $E_{\mathrm{f}}$. Such decrease in $E_{\mathrm{f}}$ may be attributed to GBAP [7-11]. On the other hand, as seen for the $\mathrm{Ta} / \mathrm{Cu} / \mathrm{Ta}$ films, Ta capping caused a decrease in $E_{\mathrm{f}}$ which was stronger with decreasing $t_{\mathrm{Cu}}$. In other words, after Ta capping, the observed values of $E_{\mathrm{f}}$ were considerably lower than the theoretical values of $E_{\mathrm{f}}$, especially for $t_{\mathrm{Cu}}<\sim 80 \mathrm{~nm}$.

Figure 5 shows examples of the $Q^{-1}$ spectra observed for a Si reed substrate with a 30 $\mathrm{nm}$ Ta buffer layer alone and for a Si reed-substrate with a $300 \mathrm{~nm} \mathrm{Cu}$ specimen film on a 30 $\mathrm{nm}$ Ta buffer layer $(\mathrm{Cu} / \mathrm{Ta})$. For the Si reed substrate with a Ta buffer layer alone, the $\mathrm{Ta}$ buffer layer was responsible for a small $Q^{-1}$ peak at $\sim 200 \mathrm{~K}$ and the gradual increase in $Q^{-1}$ 
above $\sim 250 \mathrm{~K}$ was due to the thermoelastic relaxation of the Si reed substrate [6]. After the deposition of the $\mathrm{Cu}$ specimen film, $Q^{-1}$ showed a strong and monotonic increase above $\sim 200$ $\mathrm{K}$ due to GBAP as already mentioned. $Q^{-1}$ of the $\mathrm{Cu}$ film was determined from $\Delta Q^{-1} \mathrm{Cu}$ shown in Fig. 5 and Eq. (2). For the as deposited $\mathrm{Cu} / \mathrm{Ta}$ film, $Q^{-1}{ }_{\mathrm{f}}$ showed a considerable decrease between $350 \mathrm{~K}$ and $400 \mathrm{~K}$ which was monitored as a decrease in $Q^{-1}$ at $300 \mathrm{~K}$ after annealing at $400 \mathrm{~K}, \Delta Q^{-1}{ }_{\mathrm{Cu}, 400 \mathrm{~K}}$, as shown in Fig. 5.

Figure 6(a) shows the $Q^{-1}{ }_{\mathrm{f}} v s$. $t_{\mathrm{Cu}}$ data observed for the $\mathrm{Cu} / \mathrm{Ta}$ and $\mathrm{Ta} / \mathrm{Cu} / \mathrm{Ta}$ films, where the experimental errors in the $Q^{-1}$ data were mainly associated with those in the calibrations for $\Delta Q^{-1}$ Ta. $Q^{-1}$ at $300 \mathrm{~K}$ was about $6 \times 10^{-3}$ in the $\mathrm{Cu} / \mathrm{Ta}$ films and was hardly modified by $\mathrm{Ta}$ capping. Figure $6(\mathrm{~b})$ shows the $\Delta Q_{\mathrm{f}, 400 \mathrm{~K}}^{-1} v s$. $t_{\mathrm{Cu}}$ data observed for the $\mathrm{Cu} / \mathrm{Ta}$ and $\mathrm{Ta} / \mathrm{Cu} / \mathrm{Ta}$ films. For the $\mathrm{Cu} / \mathrm{Ta}$ films, $\Delta Q_{\mathrm{f}, 400 \mathrm{~K}}^{-1}$ showed a gradual increase when $t_{\mathrm{Cu}}$ leaved from $\sim 80 \mathrm{~nm}$, i.e. a local minimum near $80 \mathrm{~nm}$. As seen for the $\mathrm{Ta} / \mathrm{Cu} / \mathrm{Ta}$ films, the $\Delta Q_{\mathrm{f}, 400 \mathrm{~K}}^{-1} v s . t_{\mathrm{Cu}}$ data were hardly modified by Ta capping too.

Figures 7 (a) and 7(b) show the STM surface images observed for the $\mathrm{Cu} / \mathrm{Ta}\left(t_{\mathrm{Cu}}=10\right.$ $\mathrm{nm})$ and $\mathrm{Ta} / \mathrm{Cu} / \mathrm{Ta}$ films $\left(t_{\mathrm{Cu}}=30 \mathrm{~nm}\right)$, respectively. It is noted that the relieves of pyramidal dips on the Si reed substrate due to the chemical etching were also observed, e.g., those with $\sim 100 \mathrm{~nm}$ square and $\sim 40 \mathrm{~nm}$ deep in Fig. 7(a) and more shallow in Fig. 7(b) due to the mild chemical etching. From the surface morphology of the $\mathrm{Cu} / \mathrm{Ta}$ and $\mathrm{Ta} / \mathrm{Cu} / \mathrm{Ta}$ films, the mean crystallite size along the surface, $D_{/ /}$, was estimated to be $\sim 10 \mathrm{~nm}$ for the $\mathrm{Cu} / \mathrm{Ta}$ film and $\sim 50$ $\mathrm{nm}$ for the $\mathrm{Ta} / \mathrm{Cu} / \mathrm{Ta}$ film, respectively. As already mentioned, $D_{\perp(111)}$ for the $\mathrm{Cu} / \mathrm{Ta}$ films was similar to $D_{/ /}$, and $D_{\perp(111)}$ was hardly modified by Ta capping. In other words, Ta capping modified $D_{/ /}$but not $D_{\perp(111)}$. Fig. 8 shows the $t_{\mathrm{Cu}}$ dependence of the root mean squire (RMS) roughness observed for the $\mathrm{Cu} / \mathrm{Ta}$ and $\mathrm{Ta} / \mathrm{Cu} / \mathrm{Ta}$ films, where the RMS roughness data for the bare Si reed substrate and the Si reed substrate with $30 \mathrm{~nm}$ thick Ta buffer layer are also indicated as a reference. The amplitude of the RMS roughness measured from that of the reference was larger for the $\mathrm{Ta} / \mathrm{Cu} / \mathrm{Ta}$ films than for the $\mathrm{Cu} / \mathrm{Ta}$ films and the local maximum was commonly observed at around $t_{\mathrm{Cu}}$ of $80 \mathrm{~nm}$.

\section{Discussion}

The characteristic property found for the nanostructured $\mathrm{Cu} / \mathrm{Ta}$ films are the decrease in $E_{\mathrm{f}}$ for $t_{\mathrm{Cu}}<\sim 80 \mathrm{~nm}$ (Fig. 4), the local minimum of $\Delta Q^{-1}{ }_{\mathrm{f}, 400 \mathrm{~K}}$ at $t_{\mathrm{Cu}}$ of $\sim 80 \mathrm{~nm}$ (Fig. 6(b)) and the local maximum of the RMS roughness at $t_{\mathrm{Cu}}$ of $\sim 80 \mathrm{~nm}$ (Fig. 8) [16]. Both the decrease in $E_{\mathrm{f}}$ for $t_{\mathrm{Cu}}<\sim 80 \mathrm{~nm}$ and the local minimum of $\Delta Q_{\mathrm{f}, 400 \mathrm{~K}}$ at $t_{\mathrm{Cu}}$ of $\sim 80 \mathrm{~nm}$ are associated with GBAP in nanostructured $\mathrm{Cu}$ and they are indicative of the magnitude of GBAP and the thermal stability of GBAP, respectively. The local maximum of the RMS roughness at $t_{\mathrm{Cu}}$ of $\sim 80 \mathrm{~nm}$ indicates that the growth mechanism of a $\mathrm{Cu}$ film was modified by additional deposition of $\mathrm{Cu}$ (the self capping effect) and a change in the self capping effects took place at $t_{\mathrm{Cu}}$ of $\sim 80 \mathrm{~nm}$. That is, the property of the grain boundary regions in nanostructured $\mathrm{Cu}$ is not on the extension from that in bulk $\mathrm{Cu}$ and not of a monotonic function of $t_{\mathrm{Cu}}$. For the $\mathrm{Cu} / \mathrm{Ta}$ films, $E_{\mathrm{f}}$ showed a considerable decrease with decreasing $t_{\mathrm{Cu}}$ below $\sim 80 \mathrm{~nm}$ although $Q^{-1}$ f remained almost constant (Figs. 4 and 6(a)), indicating that the constituent relaxed anelastic strain was mainly responsible for the decrease in $E_{\mathrm{f}}$. Such strong decrease in $E_{\mathrm{f}}$ due to the constituent relaxed anelastic strain has been found in nanocrystalline $\mathrm{Au}$ too [11].

Ta capping caused the randomize of the crystallographic texture (Fig. 3(a)), an increase in $D_{/ /}$(Fig. 7(a)), a decrease in $\sigma_{\mathrm{i} / /}$ (Fig. 3(c)) and a decrease in $E_{\mathrm{f}}$ (Fig. 4). On the other hand, no changes in $D_{\perp(111)}$ (Fig. 3(b)), $Q^{-1}$ (Fig. 6(a)), $\Delta Q^{-1}{ }_{\text {f } 400 \mathrm{~K}}$ (Fig. 6(b)) and the outline of the RMS roughness (Fig. 8) are observed after Ta capping. The randomize of the crystallographic 
texture (Fig. 3(a)), an increase in $D_{/ /}$(Fig. 7(a)), a decrease in $\sigma_{\mathrm{i} / /}$ and no changes in $D_{\perp(111)}$ indicate that Ta capping caused the grain growth along the film surface but not along the film thickness. Then, almost no changes in $Q_{f}^{-1}$ (Fig. 6(a)) and $\Delta Q^{-1}{ }_{\mathrm{f}, 400 \mathrm{~K}}$ due to Ta capping indicate that GBAP under the stress parallel to the film surface were mainly associated with the grain boundaries parallel to the film surface. On the other hand, the combination of the enhancement of the decrease in $E_{\mathrm{f}}$, the increase in $D_{/ /}$and the decrease in $\sigma_{\mathrm{i} / /}$ found after $\mathrm{Ta}$ capping indicates that the grain boundaries and the interfaces of the lamellar like films give rise the strong relaxed-anelastic-strain. In other words, since the grain boundaries and the interfaces in the nano-scale lamellar like films and interconnects can serve as a mechanical buffer layer for the low-dielectric-constant materials [1,2]. On the other hand, however, such grain boundaries and interface may also serve as a channel for mass transport for the electromigration and stressmigration. It is reported that the electromigration failure at the device operating temperature of $100{ }^{\circ} \mathrm{C}$ in real devices is induced by interface and surface diffusions [1]. The present work demonstrates that understanding of the anelastic responses of grain boundaries and interface in nano-scale $\mathrm{Cu}$ films is important for down sizing of devices.

\section{Conclusion}

The monotonic increase in $Q^{-1}$ above $200 \mathrm{~K}$ associated with GBAP was commonly observed for $\mathrm{Cu} / \mathrm{Ta}$ and $\mathrm{Ta} / \mathrm{Cu} / \mathrm{Ta}$ films. For $\mathrm{Cu} / \mathrm{Ta}$ films, $E_{\mathrm{f}}$ found for $t_{\mathrm{Cu}}>\sim 80 \mathrm{~nm}$ showed good agreement with the theoretical value. $E_{\mathrm{f}}$ observed for $t_{\mathrm{Cu}}<\sim 80 \mathrm{~nm}$ showed a decrease from the theoretical value and attributed to the relaxed anelastic strain associated with GBAP. A decrease in GBAP- $Q^{-1}$ after annealing at $400 \mathrm{~K}, \Delta Q^{-1}{ }_{\mathrm{f}, 400 \mathrm{~K}}$, and the root mean square (RMS) surface roughness showed the local minimum and the local maximum near $80 \mathrm{~nm}$, respectively, indicating that the properties of a $\mathrm{Cu}$ film were modified by subsequent deposition of a $\mathrm{Cu}$ layer (the self capping effect). For $\mathrm{Ta} / \mathrm{Cu} / \mathrm{Ta}$ films, Ta capping brought about the randomize of the crystallographic texture, an increase in the grain size parallel to the film surface, a decrease in the internal stress and a decrease in $E_{f}$ but no changes in the grain size normal to the film surface, $Q^{-1}{ }_{\mathrm{f}}, \Delta Q^{-1}{ }_{f, 400 \mathrm{~K}}$ and the outline of the RMS roughness. These results indicate that the grain boundaries and the interfaces of the lamellar like films attained after Ta capping gave rise the strong relaxed-anelastic-strain.

\section{Acknowledgement}

This work is partly supported by a Grant in Aid for Scientific Research and the $21^{\text {st }}$ Century Center of Excellence Program from the Ministry of Education, Culture, Sports, Science and

\section{References}

[1] K.N. Tu, J. Appl. Phys. 94 (2003) 5451.

[2]C.S. Hau-Riege, Microelectronics Reliability 44 (2004) 195.

[3] S. Vaidya, A.K. Sinha, Thin Solid Films, 75 (1981) 253.

[4] Y.-L. Chin, B.-S. Chiou, W.-F. Wu, Jpn. J. Appl. Phys., 41 (2002) 3057.

[5] B.S. Berry, A.C. Pritchet, J. Physique (Paris) 42 (1981) C5-1111.

[6] H. Mizubayashi, Y. Yoshihara, S. Okuda, Phys. Stat. Sol. (a) 129 (1992) 475. 
[7] Y. Kabe, H. Tanimoto, H. Mizubayashi, Mater. Trans. 45 (2004) 119.

[8] H. Mizubayashi, K. Fujita, K. Fujiwara, H. Tanimoto, J. Metastable \& Nanocrystalline Mater. 24-25 (2005) 61.

[9] N. Yagi, A. Ueki, H. Mizubayashi, H. Tanimoto, Journal of Metastable \& Nanocrystalline Materials 24-25 (2005) 503.

[10] S. Sakai, H. Tanimoto, K. Otsuka, T. Yamada, Y. Koda, E. Kita, H. Mizubayashi, Scripta Mater. 45 (2001) 1313.

[11] H. Tanimoto, S. Sakai, E. Kita, H. Mizubayashi, Mater. Trans. 44 (2003) 94.

[12] Z.Q. Sun, T.S. Ke, J. Phys. (Paris) 42 (1981) C5-451.

[13] C.-K. Hu, L. Gignac, E. Liniger, B. Herbst, D.L. Rath, S.T. Chen, S. Kaldor, A. Simon, W.-T. Tseng, Appl. Phys. Lett. 83 (2003) 869.

[14] M.J. Kobrinsky, C.V. Thompson, J. Appl. Phys. 89 (2001) 91.

[15] D. Gan, P.S. Ho, R. Huang, J. Leu, J. Maiz, T. Scherban., J. Appl. Phys. 97 (2005) 103531 .

[16] H.Tanimoto, K.Fujiwara, H.Mizubayashi, Science and Technology of Advanced Materials 6 (2005) 620.

[17] K. M. Latt, Y. K. Lee, T. Osipowicz, H. S. Park, Mater. Sci. Eng. B 94 (2002) 111. [18] J.-W. Lim, K. Mimura, K. Miyake, M. Yamashita, M. Isshiki, Jpn. J. Appl. Phys. 42 (2003) 2780.

[19] R.S. Jones, J.A. Slotwinski, J.W. Mintmire: Phys. Rev. B 45 (1992) 13624. 

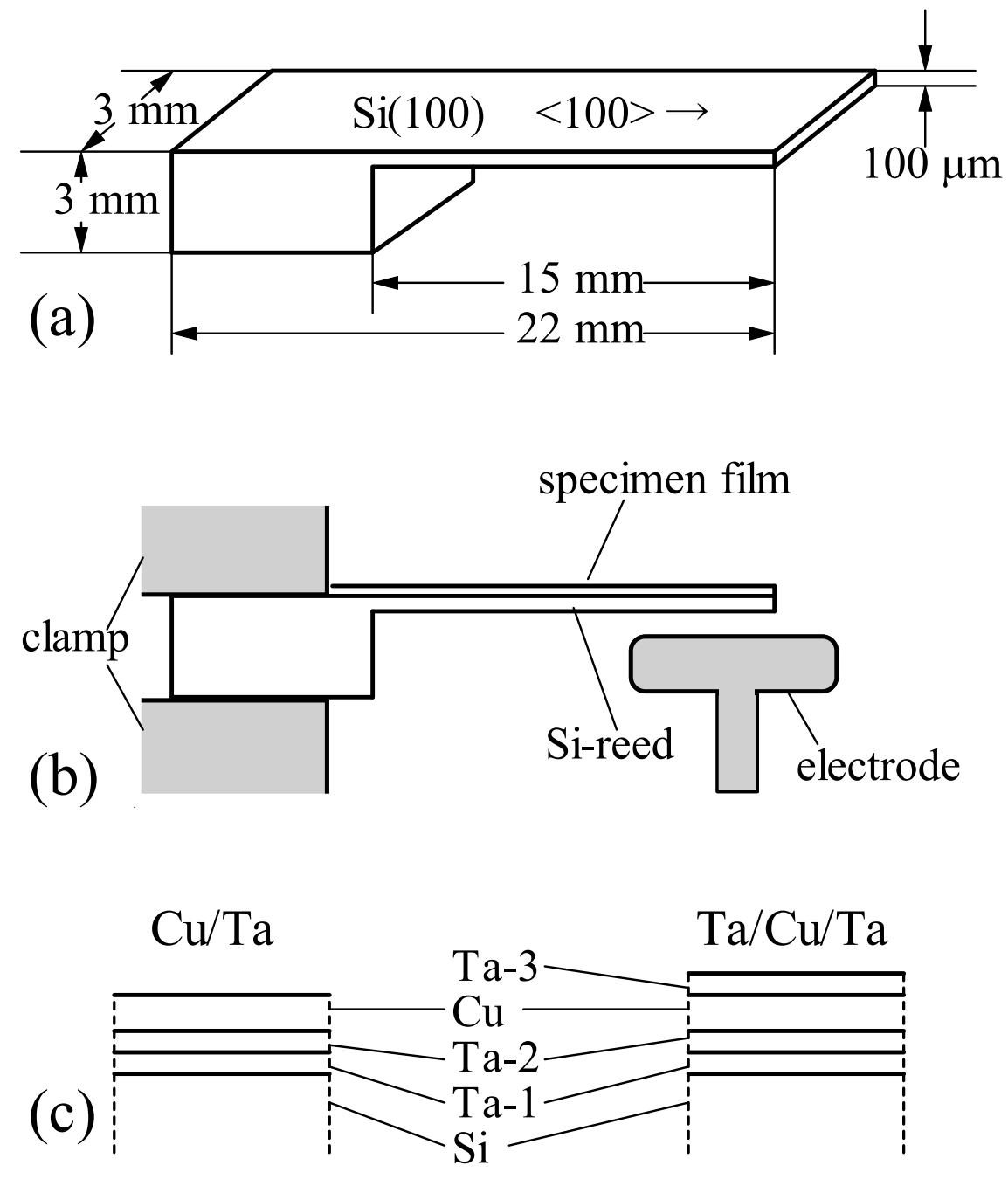

Fig. 1

Schematic diagrams : (a) a Si substrate, (b) a measurement setup, (c) cross sectional views of $\mathrm{Cu} / \mathrm{Ta}$ and $\mathrm{Ta} / \mathrm{Cu} / \mathrm{Ta}$ films. 

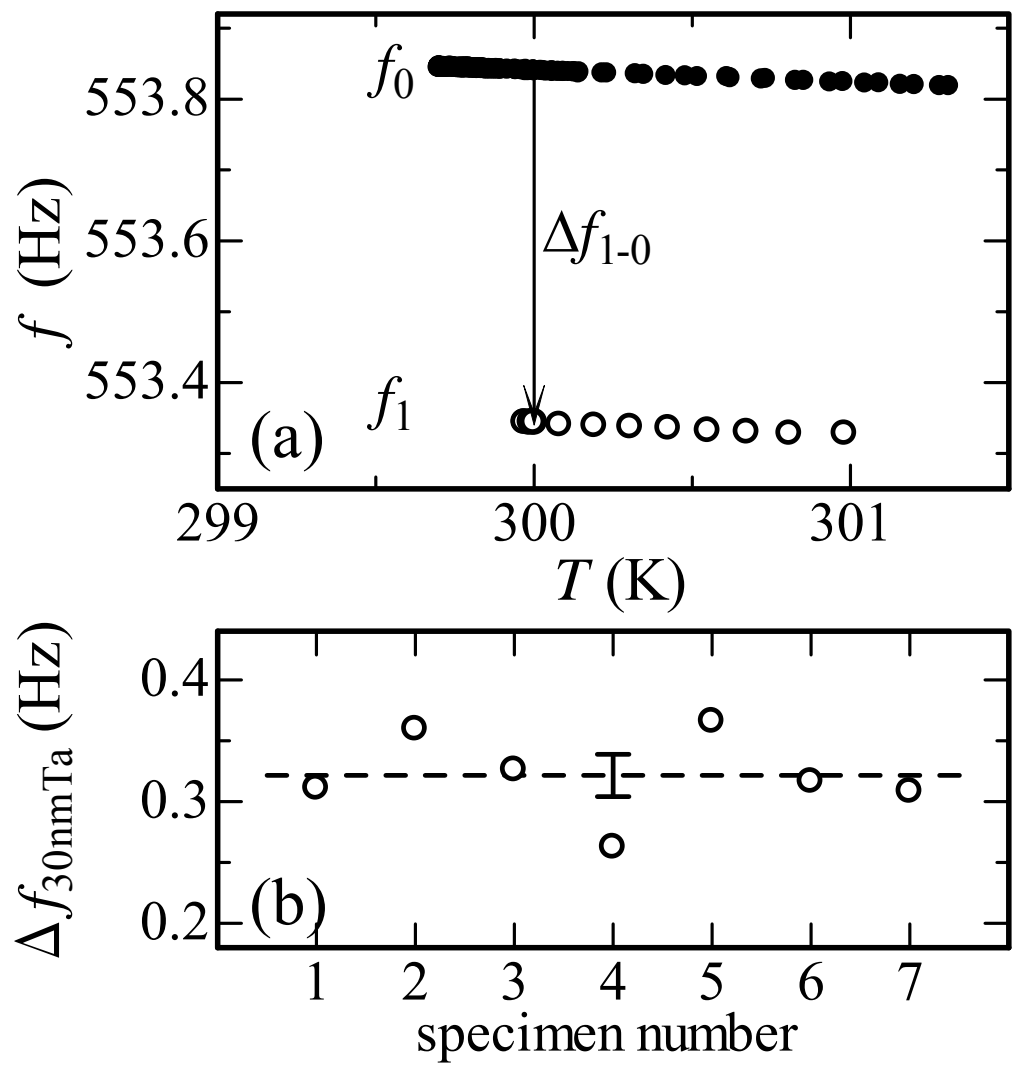

Fig. 2

(a) Examples for the $f$ measurements: $f_{0}$ and $f_{1}$ were observed for a Si-reed with the Ta-1 layer and for the Si-reed after subsequent deposition of a $40 \mathrm{~nm} \mathrm{Cu}$ specimen film following deposition of the Ta-2 layer, respectively. (b) Changes in $f$ due to deposition of the $30 \mathrm{~nm}$ Ta-2 layer, $\Delta f_{30 \mathrm{nmTa}}$, measured for seven Si-reed specimens. See text for details. 

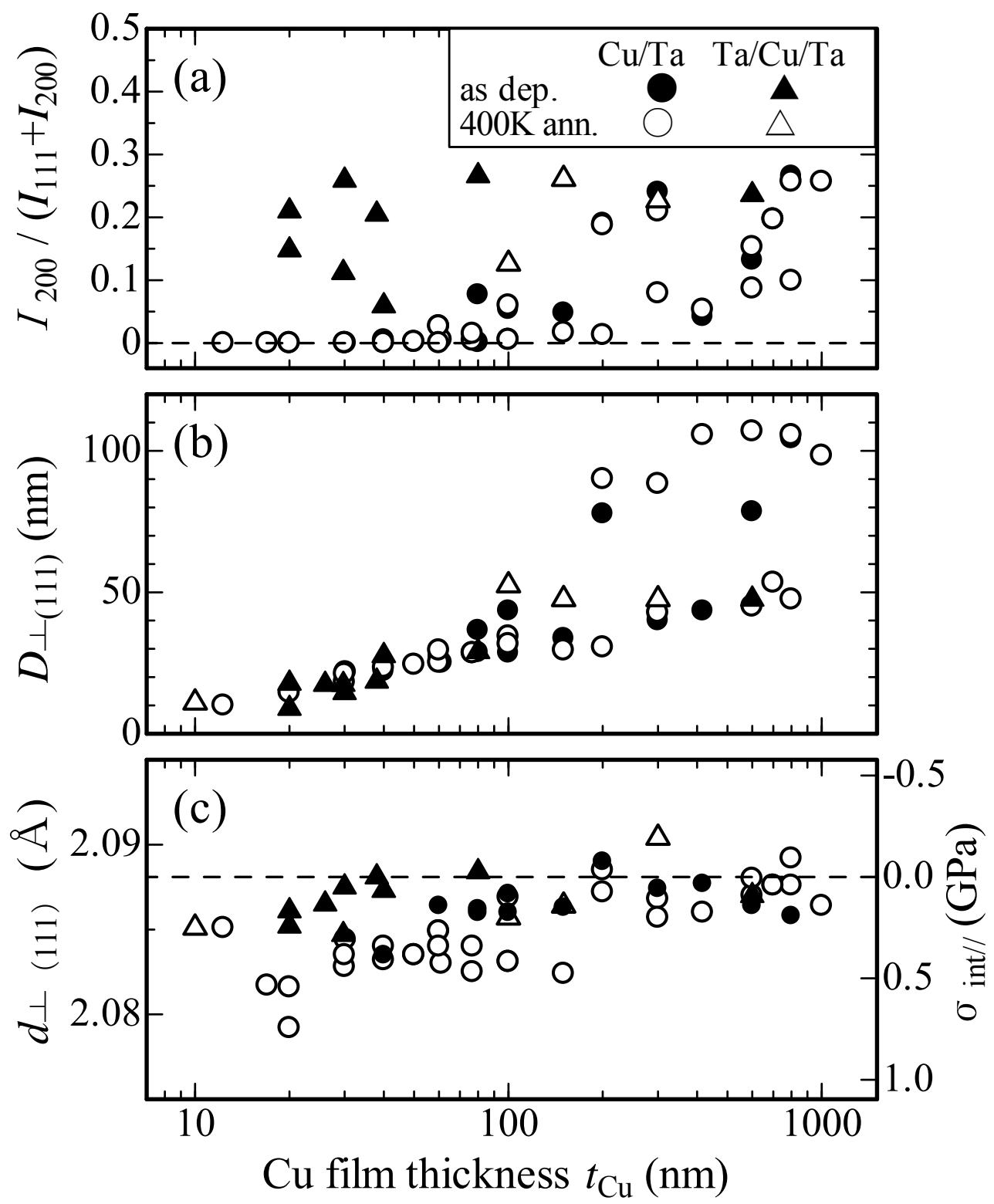

Fig. 3

The $\mathrm{Cu}$ film thickness $\left(t_{\mathrm{Cu}}\right)$ dependence of (a) the fractional intensity of the XRD 200 reflection, $I_{200} /\left(I_{111}+I_{200}\right)$, (b) the mean grain size, $D_{\perp(111)}$, and (c) the (111) plane spacing, $d_{\perp(111)}$, observed for $\mathrm{Cu} / \mathrm{Ta}$ films and $\mathrm{Ta} / \mathrm{Cu} / \mathrm{Ta}$ films. In (b), $D_{\perp(111)}$ was determined from the XRD (111) reflection and the Scherrer's equation. In (c), the internal tensile stress along the $\mathrm{Cu}$ film surface, $\sigma_{\mathrm{i} / /}$, was determined from the $d_{\perp(111)}$ data. 


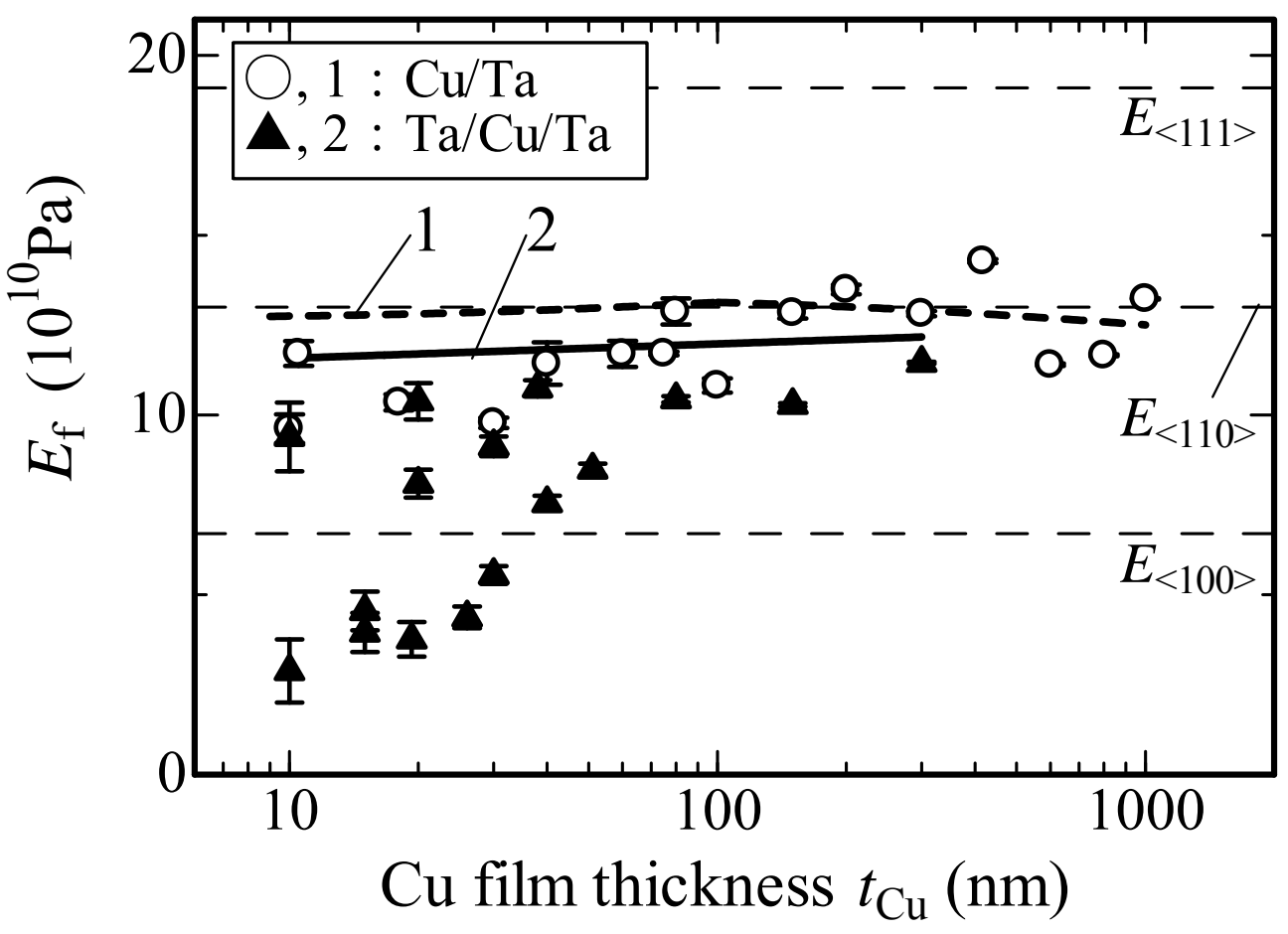

Fig. 4.

The $E_{\mathrm{f}} v s . t_{\mathrm{Cu}}$ data observed for as deposited $\mathrm{Cu} / \mathrm{Ta}$ films and $\mathrm{Ta} / \mathrm{Cu} / \mathrm{Ta}$ films. The dashed curve 1 and the solid curve 2 are the theoretical values of $E_{\mathrm{f}}$ estimated by taking into account the crystallographic texture (Fig. 3(a)) and the internal stress (Fig. 3(c)). $E_{<h k l}$ indicates the Young's modulus of $\mathrm{Cu}$ along the $<h k l>$ direction. 


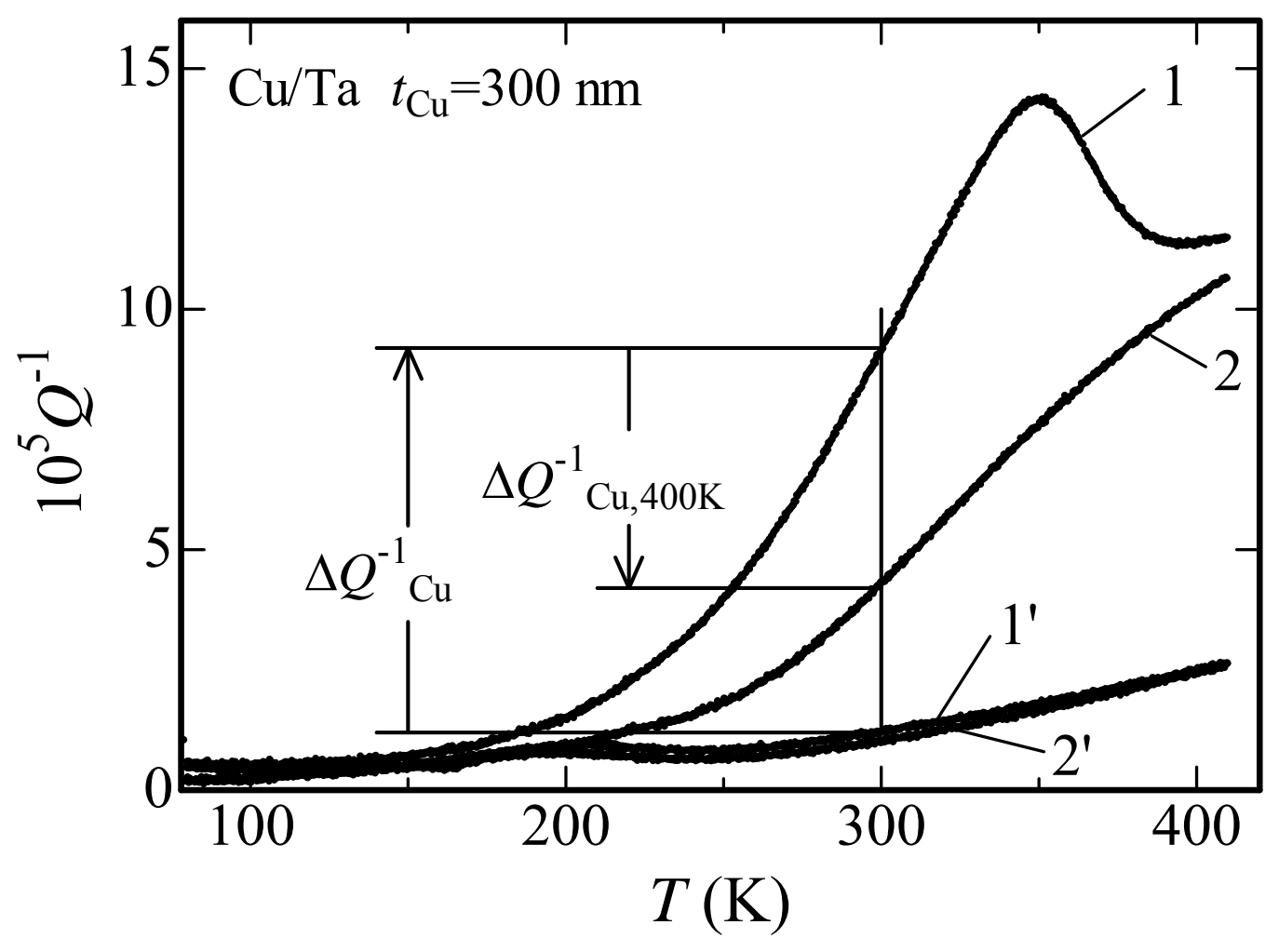

Fig. 5.

Examples of the $Q^{-1}$ vs. $T$ data observed for a Si-reed with a $30 \mathrm{~nm}$ thick Ta buffer layer alone in the as deposited state (1') and after warm up to $400 \mathrm{~K}\left(2^{\prime}\right)$ and those observed for a Si-reed with a 30 $\mathrm{nm}$ thick Ta buffer layer and $300 \mathrm{~nm} \mathrm{Cu}$ specimen film in the as deposited state (1) and after warm up to $\sim 400 \mathrm{~K}(2)$. 

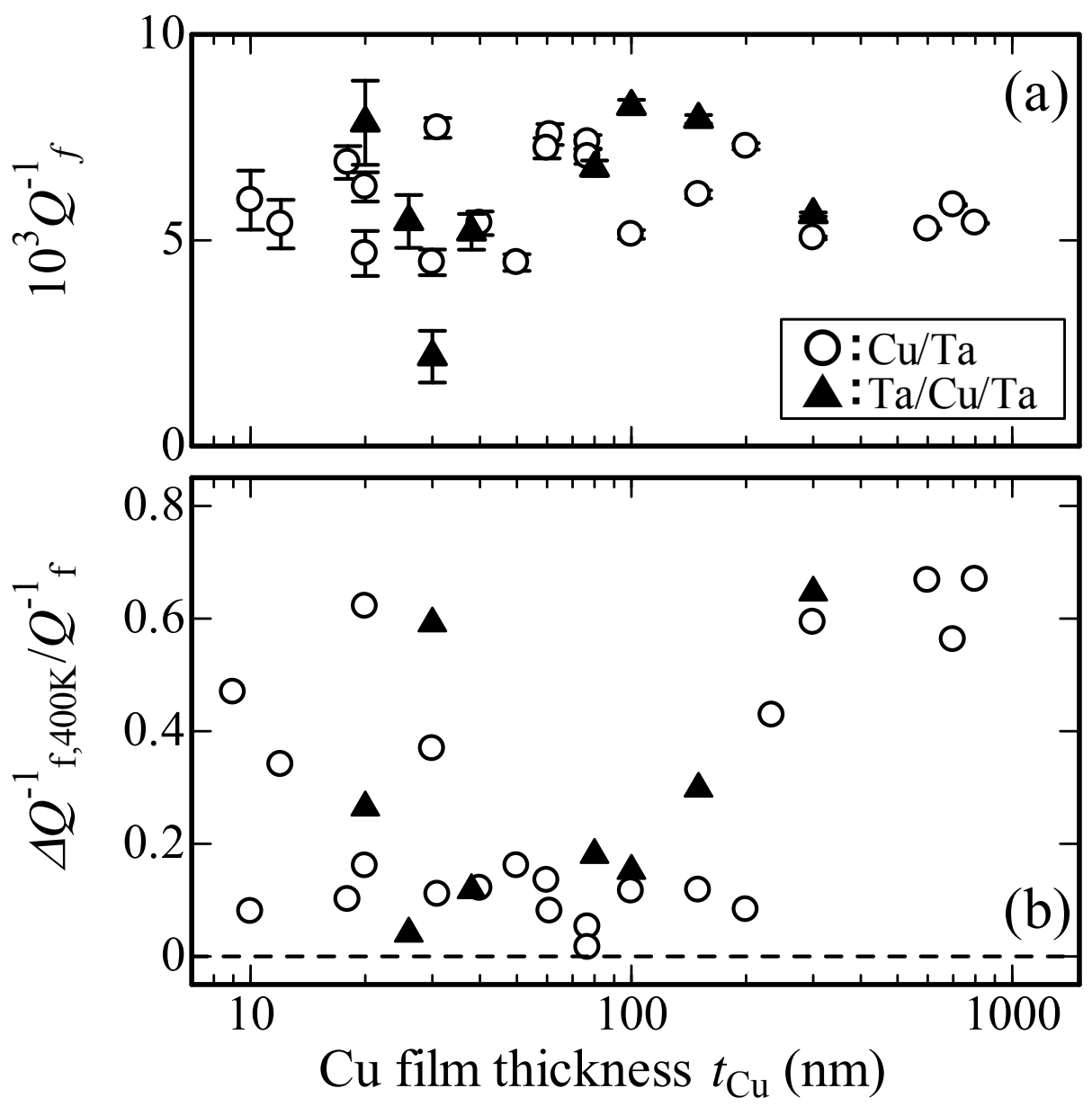

Fig. 6.

(a) The $Q^{-1}{ }_{f} v s$. $t_{\mathrm{Cu}}$ data and (b) the $\Delta Q^{-1}{ }_{f, 400 \mathrm{~K}} v s$. $t_{\mathrm{Cu}}$ data observed at $300 \mathrm{~K}$ for $\mathrm{Cu} / \mathrm{Ta}$ films and $\mathrm{Ta} / \mathrm{Cu} / \mathrm{Ta}$ films. See text for details. 

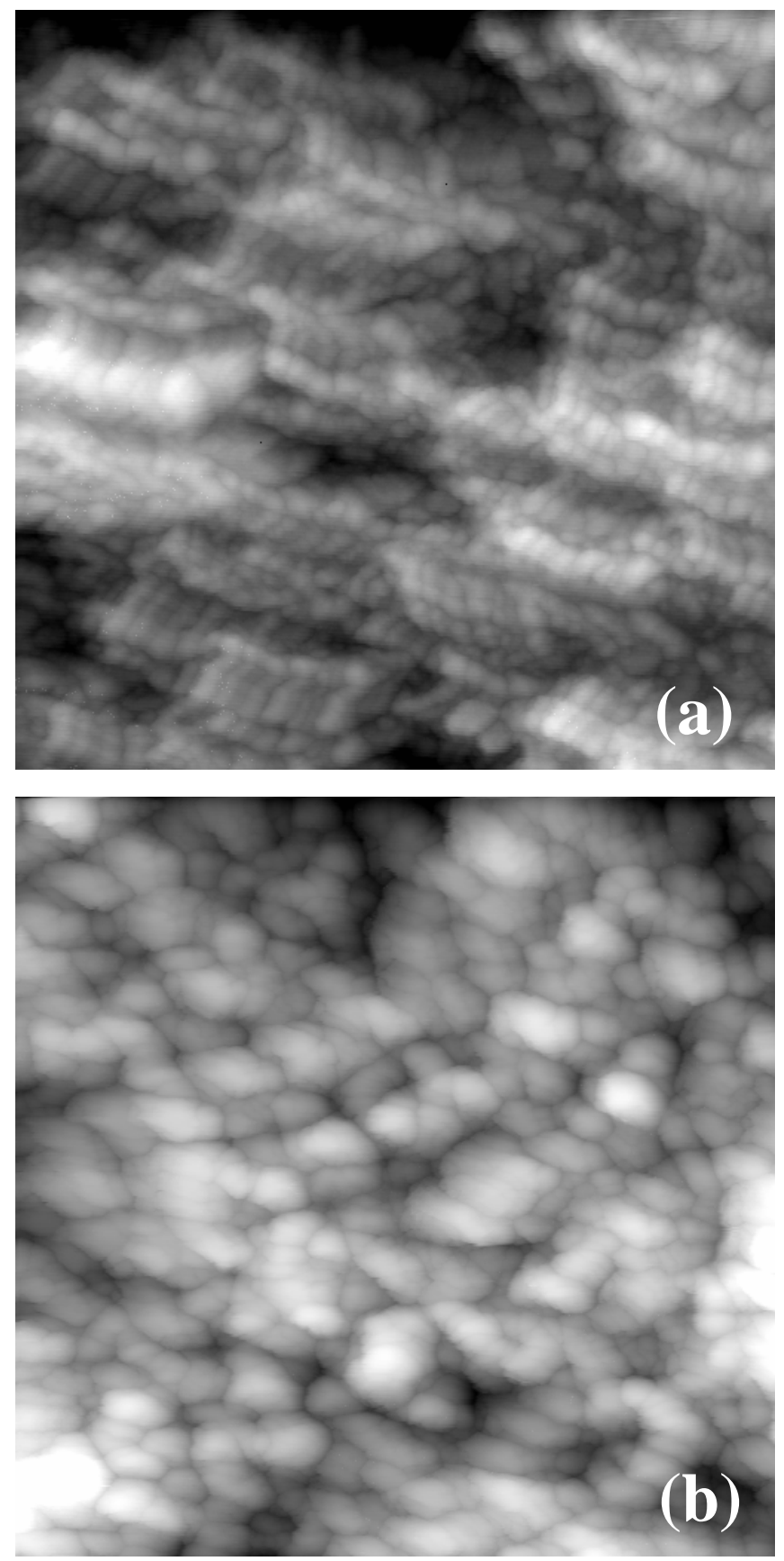

Fig. 7.

STM surface images for (a) a $\mathrm{Cu} / \mathrm{Ta}$ film with $t_{\mathrm{Cu}}=10 \mathrm{~nm}$ and (b) a Ta/Cu/Ta film with $t_{\mathrm{Cu}}=30 \mathrm{~nm}$. The $\mathrm{X}-\mathrm{Y}$ scale is $1000 \mathrm{~nm}$ and the height scale is about $50 \mathrm{~nm}$ for the both images. 


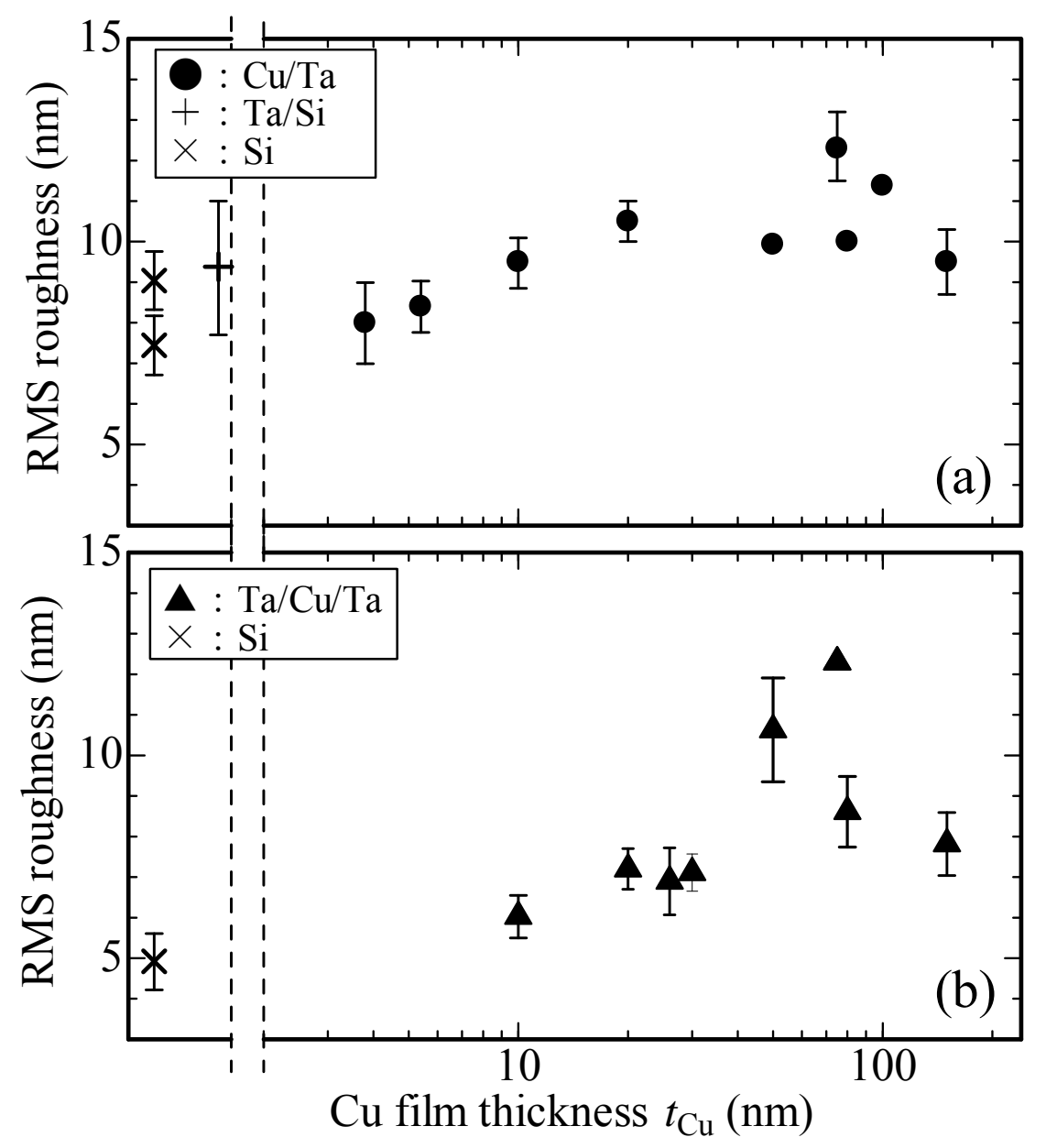

Fig. 8.

The $\mathrm{Cu}$ film thickness dependence of the root-mean-square (RMS) roughness estimated from the STM surface images for (a) $\mathrm{Cu} / \mathrm{Ta}$ films and (b) $\mathrm{Ta} / \mathrm{Cu} / \mathrm{Ta}$ films. The data observed for a Si reed substrate after etching and a Si reed substrate with a $30 \mathrm{~nm}$ Ta buffer layer are also shown. 